\title{
Architecture of Multiple Authorship
}

\author{
Sandra Denicke-Polcher and Torange Khonsari \\ The Cass. School of Architecture, London Metropolitan University
}

\section{Introduction}

The Live Projects described here run under the research title of "Architecture of Multiple Authorship" and are initiated by students and tutors with local community groups and residents. They challenge the way architecture projects with a social agenda are conventionally conceived.

Within the current discussion of shortening the architectural education in the UK and the new EU Directive $^{1}$, our Live Projects studio proposes an educational model, which adds practical experience to the academic education whilst shortening the time at university and being more competitive within the EU. The studio suggests running projects over several academic years involving different student cohorts, each participating during different phases of a project, ultimately enabling an on-going live engagement with a place and community on a project. This model could become a UK wide one to replace the current year-out practical experience (recommended by the $A R B^{2}$ ) while at the university, or a future "supervised professional traineeship"3.

The Live Projects, which are described in more detail below do not have a singular commissioner but their client body is made up of a network of partnerships between local community members, local stakeholders, our students and the tutors. They do not necessarily result in construction of a building, but have smaller temporary or permanent physical structures with strong social outcomes. Due to limited funds being available, students are required to rely on local expertise and involvement in kind as well as using discarded objects and materials for construction.

Since 2000, our ongoing research on Live Projects within the academic context has shown that one academic year is not enough to develop a meaningful project with social, economic and physical implications, embedded in concrete reality of a place. The reasons why one academic year is insufficient is:

1- Delivering teaching skills to undergraduate students at the same time as delivering a Live Project would require more than one academic year.

2- Obtaining community trust and commitment requires long-term engagement.

3- Students with an undergraduate skill set take a very long time building habitable structures.

4- Lead times for funding applications, requires one year of research and development before submission of an application.

These types of projects aim at public projects that go beyond the hardware of a building, designing its sociability, its partnerships and its economic model, that sustains it. This method of running Live Projects is to find ways for architects to make successful social projects.

To address this limitation, the model described here proposes a structure for teaching Live Projects as part of a re-evaluated architectural education in the UK, from the current $3+2+2$ years to a EU competitive $5+0$ years ${ }^{4}$. This model reflects the changing needs of the profession and responds to the recent rise in tuition fees: The time and cost reduced " $5+0$ " would mean that the practical year out experience is no longer required in order to qualify as an architect in the UK. While believing in a good balance between theory and practice, this model common to several EU countries has obvious disadvantages for a holistic architectural education. In contrast, the new protoprofessional framework proposed here, would also address the often tight job market, which can interfere 
with students' ability to find productive internships and make good use of the practical year-out.

Over the last few years the Live Project Studio continued projects beyond the academic year, which is the basis for the proposed model. This enabled our presence at one location over several years with a precise set of communities, partners and collaborators, enabling much more meaningful and successful social projects with different student cohorts. We propose that each cohort develops an aspect of the Live Project, ranging from fundraising and community outreach to developing educational, social or cultural programs to constructing small structures to host the programs. The students are taught about good practices in socially engaged Live Projects. Every year the participating student cohort learns a different skill driven by the city and its environment, however, always in relation to previous cohorts' activities whose work they take over to develop while it evolves.

Not only students benefit from the continuous involvement in a specific place. This way of working establishes links, knowledge and a presence required for making radical yet holistic changes within the city and, more precisely, its neighborhoods. Students are taught collaboration, non-hierarchical positioning of the architect as expert and potentials of multidisciplinary practice. They are equipped with insights into developing localised social, projects with minimal physical applications at low cost. This way of working makes students not only ' $\mathrm{fit}$ ' for practice, but also gives them the confidence to develop new and individual initiatives within the city for its citizens.

\section{Live Projects teaching as Academic Practice}

The methodology of our teaching of socially engaged architecture in the design studio is opposed to the current trends of a purely paper architecture education, where students look at social and political conditions in cities from a distance and take a speculative angle without concrete engagement with real situations.

At the recent ASN conference Lines Drawn ${ }^{5}$ students stressed the "importance of practices playing a role in their academic and professional training" and of "live projects ... seen as a positive step in engaging with the real world."
Each year 15-20 students, who opt for our Live Projects studio, explore how theory plays a role in innovation of practice and development of current culture in architecture. They seek new ways of practicing architecture and are asked to rethink the traditional role of the architect as a service provider and learn how to work in unconventional ways, initiating projects and redefining practice.

The studio's projects being the result of local partnerships as well as self initiated funding are presented as a "gift" to local citizens. Projects have the benefit that they can be experimental and open-ended. As there are limited funds and no singular commissioner, students have a greater influence on the project and its development.

Following this position, it is important that the students learn to become stakeholders in these projects, e.g. they remain on boards of trustees or steering committees or continue the projects into their future practice. This moves away from a traditional role of the architect as a service provider - "Agent operating for" - towards an architect who becomes collaborator and partner - "Agent operating with" 6 - towards the production of an "Architecture of Multiple Authorship".

\section{Community Live Projects}

The outcomes are engrained within relational spatial practice, where the spatiality can range from being physical, social, cultural, educational and political. It is the complex network and its relationships, that these Live Projects create, that constructs the life of the architectural project.

The clients are community groups, often in deprived areas, and projects are of public nature. All Live Projects within this studio are defined by a continuous relationship between the students and shifting members of a community group, traditionally called the "client".

On the one hand we agree with Prue Chiles's definition of Live Projects ${ }^{7}$, as being adaptable in terms of scale, ambitions, agendas and leadership and allowing them to mutate and be continued by empowered communities. However, we feel it unnecessarily limits the social outcome by restricting it to the first 6 weeks of each academic year. We prefer to define Live Projects much less 
by time. In the past our programs ran for the whole of the academic year and often involved students beyond the academic year and into their gap year. The continuous relationships and engagement with the places we are involved in and the communities we touch is extremely important. This means social interactions and relationships do not become "token".

\section{Super-Local}

At the heart of our agenda is a holistic approach. As part of this, students build 1:1 prototypes and structures using locally sourced materials, which are often collected from the local community. The negotiations, relationships and social networks created through obtaining these materials start to set up a community informed and interested in the projects.

The method of re-using materials changes the way we design as architects and contributes to an unexpected aesthetic. The discarded objects are collected and documented by the students, thus illustrating the social and spatial relationships of each physical component that creates the larger built structures.

Within these structures we act by hosting events. The varied events bring out different interests within the community, which later lead to architectural programmes for the spaces created. These programmes, which derive from local interests, become very specific to a locality. They have communities attached to them who, if constituted well, can sustain themselves.

\section{Beyond the Academic Year}

As deadlines of Live Projects with real collaborators and partners are not defined by academic hand-in dates but by real external pressures, projects which are live in nature are usually not finished within a single academic year and need to extend further.

As a consequence and in order to maintain the open nature of such projects, we have often been able to offer students the opportunity to continue working on projects in their next academic year or beyond. The freedom from the academic calendar permits ongoing engagement with a place and expanded scope for the social project.
The structure we present here is one, which sits between academic context, practice and the city. To promote this type of teaching method we suggest setting up a "Live Projects Agency" within the academic institution, where the agency acts with rather than for clients. The sites we are interested in are public and communal in occupation and primarily under public or communal ownership.

\section{Experimentation in Live Project Teaching}

We argue for architects who can become trusted partners through ongoing and open-ended engagement with a community as opposed to an architect who is a service provider with limited time resource and hope this method, once fully tested, can influence the architects scope of appointment.

Students have the potential to become partners and collaborators. This opens up new possibilities of responding to ongoing changes in a community, which are usually not possible in a conventional client and architect relationship.

We want to describe five different projects in the following to end up describing one project of the proposed study model:

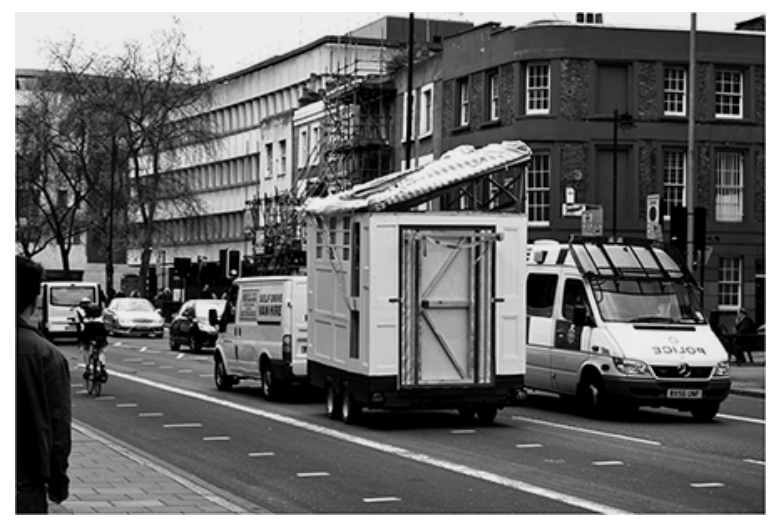

Fig. 1. Mobile Room for London

The Mobile Room for London (fig. 1) gave students the opportunity to explore hands on construction of a low cost Live/Work unit. Made entirely from re-used materials found in the local neighborhood, this taught the students how to make projects with a small budget. The room was constructed in 2008-09, but the students were not able to inhabit and test the structure fully, as the academic year 
had ended when the structure was finished. The move of the Mobile Room to a community garden, where it has been used as a community room, happened thereafter and could not be continued as an academic project as it did not comply with the academic requirements of purely running a community program. This did not have detrimental effect on the success of the space but the students missed the opportunity to participate in the empowerment of the community and further physical adjustments required to make the space work better.

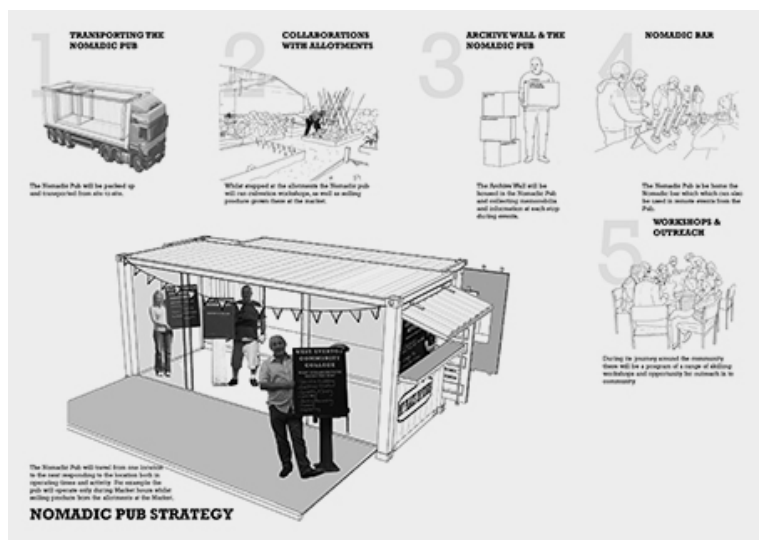

Fig. 2. The Nomadic Pub in Liverpool

The Nomadic Pub in Liverpool (fig. 2) started as a student competition in 2010. All students developed their individual proposals further within that academic year, but the project gave one student the opportunity to take it from $2^{\text {nd }}$ into $3^{\text {rd }}$ year and to work closely with the local community, a construction firm and funding bodies. At the time, the academic structure didn't equip the student to learn methods of project initiation, such as negotiating with stakeholders, the political language required to convince local authorities and fundraising skills to allow the project to continue beyond the academic year.

Two projects, the Archive Wall in Liverpool and Stalls for Mallon Gardens in Aldgate, London were successful projects. Students built up trust with local communities over several weeks and offered "gifts" - a family of built structures, which facilitated local events and festivals for the local areas in Everton, Liverpool and Aldgate, London.

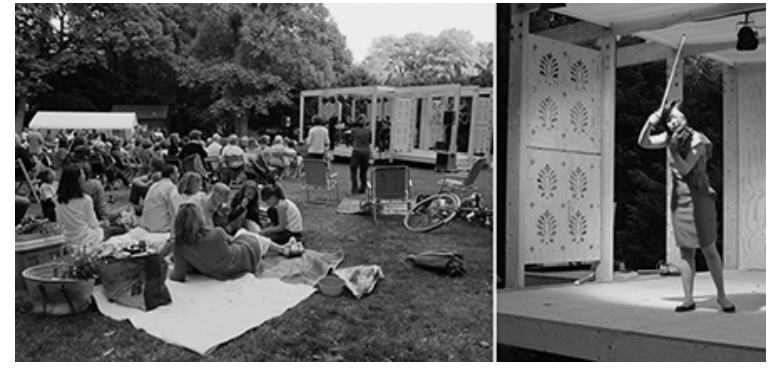

Fig. 3. Community Stage in Kronberg, Germany

The project for a Community Stage in Kronberg, Germany (fig. 3) started in 2008 without student involvement through an onsite engagement phase, called "IdeenWerkstatt", defining the community, establishing a common aim for an outdoor stage and securing funding for construction - all required to prepare the student project. In 2009-2010 students were involved in the design and competition phases and learnt how to act as community collaborators. After the academic year, only the student whose final design was chosen was sporadically involved. The experience included detailing and construction as well as amending local planning laws and developing a sustainable cultural programme of events to be run by the community.
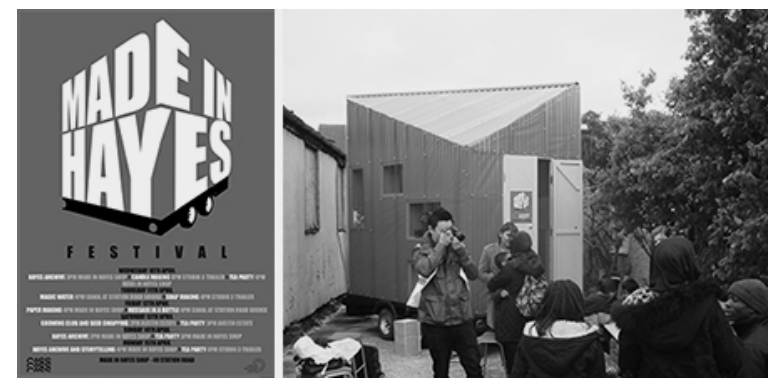

Fig. 4. Mobile Hut 2013, Hayes

In the last 2 academic years (2012-14) Studio 3 has been working on the deprived Austin Estate in Hayes, West London, in order to re-imagine its civic life and exploring the notion of a 'Town Hall' for an ethnically diverse and fragmented residential community. Starting in the first year with the construction of a Mobile Hut we explored social enterprise potentials opposite the Austin Estate. (fig 4). These enterprises included paper works, soap and candle products etc. The students saw, contrary to local perception, that the Austin Estate has interested and active residents. This gave the idea of exploring the 
traditional typology of a town hall against the contemporary context of the ethnically and culturally diverse Housing Estate. We were not interested in civic service but civic action.

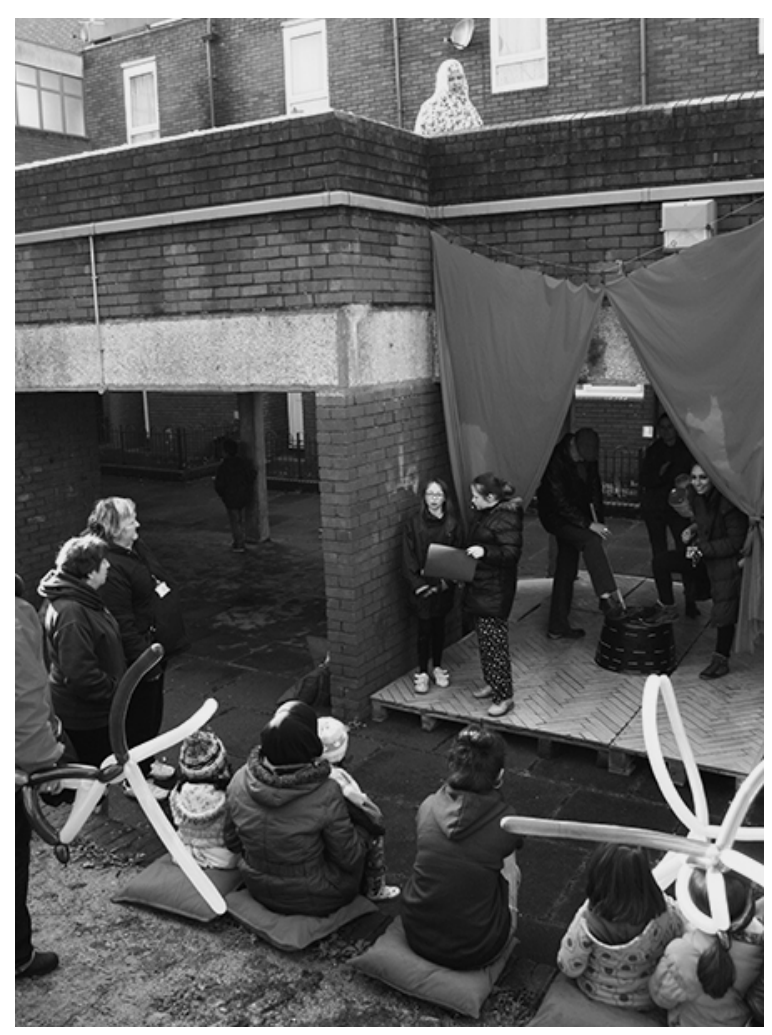

Fig. 5. Re-imagining the Town Hall 2014, Hayes

Both, during the first academic year with the Mobile Hut and the second academic year at the Austin Estate, students organized a series of events and actions (fig 5), which gave rise to the creation of different clubs on the estate, such as a sewing club, board game club and a cooking club. Clubs are effective settings for resident gathering, debate about public life and their needs. The clubs were handed over to residents and some became constituted. Students proposed fragments of joint overall schemes, developing what we call an "Architecture of Multiple Authorship" and discussing the architect's continuing responsibility of their projects in the public realm. This project will continue in order to support the development of the clubs and aims to develop the public realm strategy for the Austin Estate.

We feel strongly that for projects to be successful and holistic in a social and cultural sense, architects and students need to remain community collaborators over a long period of time, free from the academic calendar. As shown with the above projects, we often experienced social and time limitations with our projects. This is why we have developed this model, allowing academic projects to run over longer periods.

\section{Student Experience}

With the methods used, the studio teaches students "duty of care" and the values of collaboration, a sense of nonhierarchical positioning of the architect. Student feedback has demonstrated that students leaving the studio are equipped with a skill-set to develop self initiated projects. They value team-work which allows them to not solely be dependent on seeking employment but to explore and establish their own practices. ${ }^{8}$

\section{A System for the Future}

The new model proposed here could replace the current two years of practical year-out experience with students spending one year in the "Live Projects Agency", which would give students a theoretical and practical education at the same time. This would enable the current practical experience to become a university based one, at the same time shortening the architectural education to the " $5+0$ ".

The so called "Live Projects Agency", if created at the CASS, would work closely with the university based RIBA Chartered Practice CASS projects, founded in 2004. This provides the ARB credited supervision and the professional environment to the students whilst enabling it to flourish within a critical academic context.

As the project re-imagine the Town Hall in Hayes shows, our teaching has now entered methods of extending projects over several years and involve consecutive student cohorts. This way, projects can contribute to community improvement by being agile in responding to changes within the community they are working in. This is only possible as the subsequent phases of a project are conceptualised and realised over several years.

\section{A model attractive to EU students}

In the context of rising student fees, declining job 
opportunities during students' year-out and a greater competition amongst EU architects, we are therefore advocating for a shorter education in the UK, possibly without ARB Parts 1 and 2, and without the yearout experience in practice, but with a school-based yearout "externship" in the Live Projects Agency.

We would anticipate this model to also be very attractive to students from other EU countries, where the education to become a registered architect consists mostly of theory based teaching at universities without any practical experience being required. Our method, in contrast, would give students a theory and practice related architectural education that will contribute to and may provide an alternative career path, which is not the singular, prescribed mainstream profession of the architect.

\section{Notes}

${ }^{1}$ Hodder, Stephen. RIBA Council 2013: "According to the new Directive architectural training should now comprise either five years of university level training (' $5+0$ ') or not less than four years of study supplemented by a supervised professional traineeship of a minimum of two years ('4 42 ')."

${ }^{2}$ Practical Training Requirements of the ARB: Typically, 12 months of the ARB's practical training requirements are taken between $3 r d$ and 4 th year.

3 see Note 1

${ }^{4} 3+2+2$ years: 3 years full-time studies to achieve ARB Part 1,2 years full-time to achieve ARB Part 2, 2 years in practice (usually 12 months between ARB Part 1 and Part 2 and 1 year after ARB Part 2). $5+0$ years: 5 years at university without the experience in practice.

${ }^{5}$ Lines Drawn Press Release 25.03.2014. "ASN calls for changestudents discuss the state of UK architectural education".

${ }^{6}$ Petrescu, Doina. "Relationscapes: Mapping agencies of relational practice in architecture" in City, Culture and Society, volume 3, issue 2, 2012, p. 135-140.

7 Chiles, Prue. "A Live (Project) big \& small conversation, Live Projects and Alternative Ways of Practice" in IYO, Issue 1 , November 2006, p.30.

${ }^{8}$ Examples from student questionnaire conducted by Studio 3 in 2014. Questions: 1. How did the year with Studio 3 meet or change your perception of the profession of the architect? 2. What did the year with Studio 3 contribute to your current expectations of your professional career? 3. How would you want to position yourself as a future architect? Answers: Eeva, $\mathbf{2}^{\text {nd }}$ year student: 1. My perception of the profession of an architect changed quite drastically. It expanded from thinking that I'd have to adapt to a ready-made formula (a slightly boring Western male wearing black) to something a bit more fun. I learned that the skill set of an architect can be (and has to be) very broad and open. I realised how much an architect has to vary the ways of communication while trying to work with different groups (...) and how much one has to adapt. 2. It made me happier! It's somehow reassuring to know that I'll be able to use all the skills I already have, from knowing Arabic to being able to climb fences! The studio also gave me the tools and courage to start my own practice. It was important to see that very interesting projects can be self-initiated and if successful, the funding will follow. There's no need to force myself to design skyscrapers on a conveyer belt. 3. I'm interested in being an open-minded architect with broad skills working in a small practice. I'd like to continue combining research, live events and design. Halil, $\mathbf{3}^{\text {rd }}$ year student: 1 ....My time in Studio 3 taught me to look at architecture from a completely different perspective. Prior to joining the studio, I was reconsidering my choice of career and contemplating possibly moving to another area of design, due to the fact that I felt that architecture was not a field I would easily fit into, ... however my time in Studio 3 taught me to integrate my strengths and interests into my work, through exploring alternative forms of architecture and design. 2. ...Learning about alternative forms of architecture and the non-traditional infrastructures that support such projects (i.e. community initiated projects in lieu of single-client initiated and funded), has broadened my field of view of what makes up the profession... I am now more confident in my current strengths and know that I can play to them in my future career. 3. ... I would like to position myself as an individual who aims to work as part of a team. Studio 3 has been very team oriented... With each member possessing their own set of skills and knowledge, the design process becomes more effective and more efficient. Our constant work with communities is proof that wider scale input in a project leads to a richer, more successful project in the long term, and I would like to continue this ethos into my own career as an architect. Michael, $\mathbf{3}^{\text {rd }}$ year student: 1 . I have chosen Studio 3 because it promised to investigate what it means to be an architect today. ...it only reassured me that a successful architect is someone who's socially engaged and aware of the current issues. 2. It made me believe that there is a need for socially aware designers that wouldn't shy away from engaging with real people at the very early stages of the design process and be open to all the challenges that this could bring. ... 3....to me the human aspect, the real problems of real people, is always the most fascinating and the most rewarding. As an architect I would like to have a positive impact on other people and their lives and help them live in a better and fuller way by implementing clever design solutions... In one sentence - I would like to contribute to the society by producing meaningful work that is beneficial to others. 